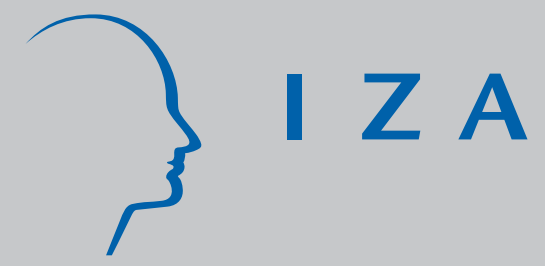

IZA DP No. 5694

Hyperbolic Discounting and Positive Optimal Inflation

Liam Graham

Dennis J. Snower

May 2011

Forschungsinstitut zur Zukunft der Arbeit Institute for the Study of Labor 


\title{
Hyperbolic Discounting and Positive Optimal Inflation
}

\author{
Liam Graham \\ University College London \\ Dennis J. Snower \\ Kiel Institute for the World Economy, \\ Christian-Albrechts University Kiel, CEPR and IZA
}
Discussion Paper No. 5694
May 2011

IZA

P.O. Box 7240

53072 Bonn

Germany

Phone: +49-228-3894-0

Fax: +49-228-3894-180

E-mail: iza@iza.org

\begin{abstract}
Any opinions expressed here are those of the author(s) and not those of IZA. Research published in this series may include views on policy, but the institute itself takes no institutional policy positions.

The Institute for the Study of Labor (IZA) in Bonn is a local and virtual international research center and a place of communication between science, politics and business. IZA is an independent nonprofit organization supported by Deutsche Post Foundation. The center is associated with the University of Bonn and offers a stimulating research environment through its international network, workshops and conferences, data service, project support, research visits and doctoral program. IZA engages in (i) original and internationally competitive research in all fields of labor economics, (ii) development of policy concepts, and (iii) dissemination of research results and concepts to the interested public.
\end{abstract}

IZA Discussion Papers often represent preliminary work and are circulated to encourage discussion. Citation of such a paper should account for its provisional character. A revised version may be available directly from the author. 
IZA Discussion Paper No. 5694

May 2011

\section{ABSTRACT}

\section{Hyperbolic Discounting and Positive Optimal Inflation}

The Friedman rule states that steady-state welfare is maximized when there is deflation at the real rate of interest. Recent work by Khan et al (2003) uses a richer model but still finds deflation optimal. In an otherwise standard new Keynesian model we show that, if households have hyperbolic discounting, small positive rates of inflation can be optimal. In our baseline calibration, the optimal rate of inflation is $2.1 \%$ and remains positive across a wide range of calibrations.

JEL Classification: E20, E40, E50

Keywords: optimal monetary policy, inflation targeting, unemployment, Phillips curve, nominal inertia, monetary policy

Corresponding author:

Liam Graham

Department of Economics

University College London

Gower Street

London WC1E 6BT

United Kingdom

E-mail: Liam.Graham@ucl.ac.uk 


\section{Introduction}

The Friedman rule states that optimal monetary policy in the long run requires deflation at the real rate of interest. More recent work by Khan et al (2003) uses a richer model in which inflation or deflation has costs arising from price dispersion. They find the optimal rate of inflation to be higher than the Friedman rule, but still negative. Nevertheless policymakers have chosen positive inflation targets based on other criteria.

The central result of this paper is that, if households have hyperbolic discounting and there are multi-period nominal wage contracts, low positive inflation rates can be optimal. Our baseline calibration implies an optimal rate of $2.1 \%$, and we show that small positive rates between $1 \%$ and $4 \%$ are optimal over a wide range of calibrations.

To understand intuitively why hyperbolic discounting has this effect, it is important to realize that inflation redistributes the costs and benefits of employment through time. In particular, since a worker's nominal wage is constant over the wage contract period while the price level rises continually, the real wage falls over this contract period. Thus the worker's disutility of labour is distributed from the present (when the real wage is relatively high and working hours corresponding low) to the future (when the wage is low and working hours are high). Under hyperbolic discounting the future receives much less weight than the present. Since the worker attaches relatively little importance to the future disutility of labour, she is inclined to set a wage which implies a higher average level of labour over the contract period.

The greater the inflation rate, the more the disutility of labour is shifted into the future. Thus the myopia inherent in hyperbolic discounting has a stronger effect, and so aggregate employment rises: there is a long-run positive relation between inflation and employment. This relation can provide a useful long-run role for monetary policy. Specifically, under imperfect competition and other market imperfections (such as income taxes), the equilibrium level of output and employment is inefficiently low. But by letting the money supply grow and thereby generating inflation, the monetary authority can stimulate long-run macroeconomic activity, thereby offsetting the imperfections. It turns out that, on this account, 
the optimal long-run inflation rate becomes positive.

For a positive rate of inflation to be optimal two conditions must be satisfied.

1. The zero-inflation steady state must be inefficient. In our model this arises from two sources: imperfect competition among firms and a labour income tax. It is this inefficiency which monetary policy can potentially address.

2. There exists, at least over some range of inflation above zero, a positive tradeoff between inflation and real macroeconomic activity, such as production or employment. There are a number of possible theoretical justifications for the existence of such a tradeoff, among them are downward nominal wage rigidities; "greasing the wheels" of the labour market; the optimality of seigniorage when only distortionary taxes are available and the zero-lower bound on nominal interest rates. Reviews can be found in Sinclair (2003) or Billi and Khan $(2008)^{1}$. In this paper we focus on the role of discounting.

Conventional New Keynesian models take account of the first condition (through their assumption that prices and/or wages are set under monopolistic competition), but not the second. The fact that discounting leads to a positive trade off is well known in the literature (Romer, 1990; Ascari, 1998; Graham and Snower, 2004, Levin and Yun, 2007). Yet with exponential discounting, the discount rate is close to zero and this positive tradeoff is very small and only exists over a very small range of inflation. In short, macroeconomic activity is inefficiently low, but monetary policy is virtually powerless to do anything to raise it.

We show that the second condition becomes important under hyperbolic discounting, whereby households have a strong preference for a payoff today over a payoff tomorrow, but a much weaker preference for a payoff in a year's time over a payoff in a year and a day's time (Laibson, 1997, Barro 1999$).^{2}$

\footnotetext{
${ }^{1}$ There is also a literature finds a zero rate of inflation optimal by analysing the effects of steady state inflation on growth, for example Gomme (1993) and Amano and Moran (2008).

${ }^{2}$ Barro (1999) shows that such high short-run discount factors are compatible with observed market returns and that there exists an "observational equivalence" between an economy with hyperbolic discounting and one with exponential discounting. Graham and Snower (2008) show that the presence of nominal wage contracts breaks this observational equivalence in the sense that an econometrician estimating both the Euler equation and the long-run Phillips curve could distinguish an economy with hyperbolic discounting from one with exponential discounting.
} 
The optimal rate of inflation is a function of the relative strengths of the different channels by which inflation affects real activity. In this paper, we present a simple New Keynesian model with households who choose between consuming goods by paying cash, which is subject to the inflation tax, or credit, which incurs a time cost. Households supply differentiated labour to firms who face a production function involving a Dixit-Stiglitz aggregate of labour types. Households set nominal wages by means of Taylor contracts ${ }^{3}$.

In this model there are five channels (described in detail in Section 4) by which inflation affects real variables. The first two of these channels are sources of the inflation tax: (i) "the wedge of monetary inefficiency" (the part of the inflation tax due to interest foregone on cash held) and (ii) "shopping time" (inflation raises the nominal interest rate and thereby induces households to substitute credit for cash, thereby incurring a shopping time cost). These imply a negative relation between welfare and the rate of inflation. If only these two channels are present, the Friedman rule applies and optimal monetary policy is to deflate at the real rate of interest.

In the presence of inflation, nominal wage contracts imply relative price instability in the form of wage dispersion. The third and fourth channels represent the effect of this wage dispersion on firms and households, respectively: (iii) "employment cycling" (inflation generates inefficient employment fluctuations due to fluctuations in households' real wages, in the presence of staggered nominal wage contracts) and (iv) "labour supply smoothing" (the employment fluctuations make households worse off, due to rising disutility of labour). These channels imply a negative relation between welfare and the absolute value of inflation. Considering only these two channels, the optimal inflation rate is zero: Thus in a model with the first four channels the optimal inflation rate will lie between zero and the Friedman rule. This is effectively the model of Khan et al (2003).

The final channel is (v) "discounting" (a higher discount rate leads households' attaching less weight to the disutility from future work and, given a rising profile of labour over the wage contract, leads households to set a lower wage which means they supply more labour). As we noted above, discounting leads to a positive relation between inflation and output and employment. However the welfare ef-

\footnotetext{
${ }^{3}$ Another possibiliy would be Calvo contracts. We discuss our choice in section 6.1 .
} 
fects of this are theoretically ambiguous as increased output increases welfare but increased employment reduces welfare. In this paper we show that, under our baseline calibration, while optimal inflation without discounting is $-1.2 \%$ (corresponding to Khan et al's, 2003 result), if we introduce hyperbolic discounting the optimal rate becomes $2.1 \%$.

Our result relies crucially on the interaction of nominal wage contracts and hyperbolic discounting. There is considerable empirical support for both of these features of the economy. For a review of the literature on hyperbolic discounting, see Laibson, 1997. We review the evidence for the existence of nominal wage contracts in section 6.2 .

The paper is organized as follows. Section 2 presents the model. Section 3 explains the five channels by which inflation affects real activity in the model. Section 4 gives our choice of parameters. Section 5 presents our benchmark result, explains the contribution of each of the five channels and conducts sensitivity analysis. In section 6 we discuss the our assumptions on the nature of the wage contract, and draw some implications for monetary policy. Section 7 concludes. The Appendix contains the solution of the household's problem and further derivations are available from the corresponding author's website.

\section{Model}

We present a simple dynamic general equilibrium model consisting of three types of agent: households, firms and a government. There is no uncertainty, and in our results section we focus on steady states of the model.

A large number $S$ of households supply differentiated labour to firms and consume goods. Households can choose whether to purchase goods with cash or with nominal credit, which incurs a time cost. In the spirit of Taylor (1979), we group households into $N$ wage-setting cohorts of equal size, each of which sets a nominal wage contract for $N$ periods. Different cohorts set wages at different times, uniformly staggered.

Firms use all labour types to produce a homogeneous consumption good. The government imposes a tax on labour income, prints money and rebates the proceeds to households as a lump sum. 


\section{$2.1 \quad$ Firms}

The representative firm uses all types of labour in a production function with a constant elasticity of substitution (Dixit and Stiglitz, 1977) to produce a homogenous consumption good:

$$
y_{t}=\left[\sum_{h=0}^{S} n_{t}(h)^{\frac{\theta-1}{\theta}}\right]^{\frac{\theta}{\theta-1}}
$$

where $y_{t}$ is output, $n_{t}(h)$ is the amount of labour hired from household $h$, and $\theta$ is the elasticity of substitution between different labour types.

There is perfect competition in the product market. The firm's cost-minimization implies a standard demand function for each household's labour:

$$
n_{t}(h)=w_{t}(h)^{-\theta} y_{t}
$$

where $w(h)$ is the real value of the nominal wage set by household $h$. Note that since firms are perfect competitors their markup will be zero and the real wage index constant and equal to unity.

\subsection{Households}

A typical household $h$ maximizes its lifetime utility defined over consumption $c$ and leisure $l$

$$
U_{t}(h)=\sum_{i=0}^{\infty} \beta_{t: t+i} u\left(c_{t+i}(h), l_{t+i}(h)\right)
$$

We write the discount factor between periods $t$ and $t+i$ in the general form $\beta_{t: t+i}$ to allow different specifications.

In what follows we restrict ourselves to utility functions of the following form

$$
u(c, l)=\log c+\zeta \frac{l^{1-\eta}}{1-\eta}
$$

Households maximize their utility subject to a budget constraint, written in real terms as 


$$
m_{t}(h)+\frac{1}{1+R} b_{t+1}(h)=\frac{b_{t}(h)-d_{t}(h)}{1+\pi}+(1-\tau) w_{t}(h) n_{t}(h)+\chi_{t}
$$

where $m$ is real money balances, $d$ is credit used to buy goods, $\chi$ are lump-sum transfers from government, and $n$ is time spent working. $R$ and $\pi$, the nominal rate of interest and the inflation rate respectively, we assume to be constant ${ }^{4}$. Holdings of one-period nominal bonds, which pay a unit on redemption, are given by $b$.

Households face a choice between buying goods with cash, and buying them with nominal credit. If the proportion of goods bought with credit is $\xi$, the household's holdings of real money balances are given by

$$
m_{t}(h)=\left(1-\xi_{t}(h)\right) c_{t}(h)
$$

and holdings of nominal consumption debt, repayable in the next period, are

$$
d_{t+1}(h)=\xi_{t}(h) c_{t}(h)
$$

To model the split between cash and credit goods, we follow Khan et al (2003) by assuming that buying goods with credit involves a cost in terms of "shopping time", $n^{s}$. Then if we normalize the total time endowment to unity, the household's time constraint is

$$
l_{t}(h)+n_{t}(h)+n_{t}^{s}(h)=1
$$

We follow Khan et al (2003) in interpreting the single consumption good as a continuum of goods, and modeling the cash / credit split by assuming that if credit is used, the purchase involves a random fixed time cost $\varpi$ which is only known after the consumer has chosen how much of the good to buy, but before the decision to buy it with cash or credit. If $F$ is the cumulative distribution function

\footnotetext{
${ }^{4}$ Since our results will relate only to steady states there is no loss of generality here
} 
of time costs, total time costs borne by household $h$ are then

$$
n_{t}^{s}(h)=\int_{0}^{F^{-1}\left(\xi_{t}(h)\right)} \varpi d F(\varpi)
$$

The household also faces the downward sloping demand curves for the household's labour type (2) and the constraint that it can only change its wage every $N$ periods.

\subsection{Government}

Government revenue arises from a proportional tax $\tau$ on labour income and from seigniorage. There is no government spending and proceeds are rebated to households equally by lump-sum transfers $\chi$, so that the government budget constraint is

$$
\tau \sum_{h=0}^{S} w_{t}(h) n_{t}(h)+\left(m_{t}-\frac{m_{t-1}}{1+\pi}\right)=N \chi_{t}
$$

The government follows an exogenous rule for the money supply with a constant growth rate $g$ and this gives steady state inflation, $\pi=\Delta m=g$.

\subsection{Aggregates}

In the absence of government spending, the aggregate budget constraint is

$$
y_{t}=c_{t}
$$

We define aggregate labour as

$$
n_{t}=\sum_{h=0}^{S} n_{t}(h)
$$

and the aggregate wage index in terms of efficiency labour is 


$$
w_{t}=\left[\sum_{h=0}^{S} w_{t}(h)^{1-\theta}\right]^{\frac{1}{1-\theta}}
$$

The real interest rate is given by

$$
r=R-\pi
$$

which is constant in a given steady state since $R$ and $\pi$ are assumed constant.

\subsection{Equilibrium}

A competitive equilibrium for the above economy is a sequence of plans for

- allocations of households ${ }^{5}\left\{m_{t}(h), d_{t+1}(h), b_{t+1}(h), n_{t}^{s}(h), n_{t}(h)\right\}_{t=1: \infty}^{h=1: \infty}$

- prices $\left\{w_{t}(h), r\right\}_{t=1: \infty}^{h=1: \infty}$

- aggregate labour input $\left\{n_{t}\right\}_{t=1: \infty}$

such that

1. Given prices, the allocations solve the utility maximization problem. If preferences are time-inconsistent, the allocations are also Nash equilibria of the game-theoretic problem of each household.

2. $\left\{w_{t}\right\}_{t=1: \infty}$ is the marginal product of aggregate labour (12).

3. Product, money and bond markets clear.

\subsection{Discounting}

With exponential discounting, the household's discount factor is constant through time, $\beta_{t: t+i}=\beta^{i}$. To model hyperbolic discounting, we follow Laibson $(1996,1997)$ and much of the subsequent literature, in approximating the hyperbolic discount function by a "quasi-hyperbolic" discount function in which the discount factors

\footnotetext{
${ }^{5}(6)$ and (7) allow this to be written either in terms of money $m$ and consumption debt holdings $d$ or consumption $c$ and the credit goods split $\xi$
} 
from the perspective of the current period are $1, \gamma \delta, \gamma \delta^{2}, \gamma \delta^{3} \ldots$. The discount factor between the first two periods is $\gamma \delta$; but that between all subsequent periods is $\delta$. Thus we can think of $\gamma$ as a short-run discount factor, and $\delta$ as a long-run discount factor.

In this case the household's behavior is time-inconsistent: in future periods the household will have an incentive to change plans made in the current period. Since the household cannot commit itself to a plan beyond the current period and since a household with rational expectations will take this into account when making its decisions, it is standard practice (e.g. Laibson, 1996) to formulate the household's problem as a game played by the household at time $t$ (self $t$ ) against the household in future periods (future selves).

\subsection{Solving the household's problem}

We show in Appendix A that the equilibrium strategy ${ }^{6}$ of an infinitely-lived household with preferences (3) facing constraints (2), (5) and (8) and able to reset its nominal wage every $N$ periods is

$$
\begin{aligned}
& s_{t}(h)=\left\{c_{t}^{*}(h), \xi_{t}^{*}(h)\right\}: t \neq i N \\
& s_{t}(h)=\left\{c_{t}^{*}(h), \xi_{t}^{*}(h), w_{t}^{*}(h)\right\}: t=i N
\end{aligned}
$$

where the real value of the nominal wage the household chooses when it can change its wage is

$$
w_{t}^{*}(h)=\omega \frac{\sum_{i=0}^{N-1} \beta_{t: t+i} l_{t+i}^{*-\eta}(h) n_{t+i}^{*}(h)}{\frac{1}{N c_{t}^{*}(h)\left(1+R\left(1-\xi_{t}^{*}(h)\right)\right)} \sum_{i=0}^{N-1} \frac{n_{t+i}^{*}(h)}{(1+\pi)^{i}}}
$$

where $\omega=\frac{\zeta \theta\left(1-(1+r)^{-1}\right)}{(\theta-1)(1-\tau)\left(1-(1+r)^{-N}\right)}$.

${ }^{6}(2),(8)$ and $(9)$ show that choosing a strategy in terms of the wage and the proportion of goods to buy with credit $\{w, \xi\}$; is equivalent to choosing one in terms of the time to allocate to employment and shopping activities $\left\{n, n^{s}\right\}$. On this account, $l_{t}^{*}(h)$ is not listed as an argument of the household's equilibrium strategy. 
The proportion of credit goods is defined implicitly by

$$
\xi_{t}^{*}(h)=F\left(\frac{R}{\zeta l_{t}^{*}(h)^{-\eta}\left(1+R\left(1-\xi_{t}^{*}(h)\right)\right)}\right)
$$

and consumption is a constant fraction of $a_{t}$ the household's lifetime wealth,

$$
c_{t}^{*}(h)=\frac{r}{1+R\left(1-\xi_{t}^{*}(h)\right)} a_{t}(h)
$$

This differs from the standard permanent income result that consumption is the annuity value of wealth, $r a(h)$, due to the distortionary effects of inflation, equivalent to a proportional tax on consumption, discussed in section 3.5. Comparing (17) and (18) with the equivalent equations (34) and (35) in Khan et al (2003) shows that the equilibrium strategy is of the same form as the optimal choice in a time-consistent world.

\subsection{The steady state}

For the remainder of the paper we consider the properties of a symmetric steady state in which all households consume the same amount in all periods ${ }^{7}$ and, when they can reset their wage, choose a nominal wage to obtain the same real wage.

Households set nominal wages every $N$ periods. Since contracts are set in staggered fashion, under non-zero inflation the $N$ different cohorts charge $N$ different real wages (the highest charged by the cohort which sets its wage this period; the lowest charged by the cohort which set its wage $N-1$ periods ago). In short, the economy is characterized by real wage dispersion.

An important feature of this steady state is that the intertemporal distribution of real wages across the contract period is identical to the intratemporal distribution of wages between cohorts. This can be seen from a simple example involving $N=4$ with four cohorts setting wage contracts lasting four periods. Whenever a cohort resets its wage, it chooses a nominal wage to give a real wage $w^{*}$. In

\footnotetext{
${ }^{7}$ In the absence of redistribution, different cohorts would have (very slightly, under the range of inflation rates we consider in the paper) different present values of lifetime wealth because they start time in different periods of the wage contract. In Appendix B of the working paper version, available on the corresponding author's website, we show the start-of-time redistribution necessary to remove this asymmetry.
} 
the next period, the real value of this is $\frac{w^{*}}{1+\pi}$, and so on. Table $1 \mathrm{a}$ and $\mathrm{b}$ show the resulting nominal and real wage distributions.

Table 1a: Nominal wage distribution in the steady state

\begin{tabular}{|l|l|l|l|l|l|}
\hline & & \multicolumn{5}{|l|}{ Nominal wage of cohort... } \\
\hline Period & Price level & 1 & 2 & 3 & 4 \\
\hline 1 & 1 & $w^{*}$ & $\frac{w^{*}}{(1+\pi)^{3}}$ & $\frac{w^{*}}{(1+\pi)^{2}}$ & $\frac{w^{*}}{1+\pi}$ \\
\hline 2 & $1+\pi$ & $w^{*}$ & $w^{*}(1+\pi)$ & $\frac{w^{*}}{(1+\pi)^{2}}$ & $\frac{w^{*}}{1+\pi}$ \\
\hline 3 & $(1+\pi)^{2}$ & $w^{*}$ & $w^{*}(1+\pi)$ & $w^{*}(1+\pi)^{2}$ & $\frac{w^{*}}{1+\pi}$ \\
\hline 4 & $(1+\pi)^{3}$ & $w^{*}$ & $w^{*}(1+\pi)$ & $w^{*}(1+\pi)^{2}$ & $w^{*}(1+\pi)^{3}$ \\
\hline
\end{tabular}

Table 1b: Real wage distribution in the steady state

\begin{tabular}{|l|l|l|l|l|}
\hline & \multicolumn{4}{|c|}{ Real wage of cohort... } \\
\hline Period & 1 & 2 & 3 & 4 \\
\hline 1 & $w^{*}$ & $\frac{w^{*}}{(1+\pi)^{3}}$ & $\frac{w^{*}}{(1+\pi)^{2}}$ & $\frac{w^{*}}{1+\pi}$ \\
\hline 2 & $\frac{w^{*}}{1+\pi}$ & $w^{*}$ & $\frac{w^{*}}{(1+\pi)^{3}}$ & $\frac{w^{*}}{(1+\pi)^{2}}$ \\
\hline 3 & $\frac{w^{*}}{(1+\pi)^{2}}$ & $\frac{w^{*}}{1+\pi}$ & $w^{*}$ & $\frac{w^{*}}{(1+\pi)^{3}}$ \\
\hline 4 & $\frac{w^{*}}{(1+\pi)^{3}}$ & $\frac{w^{*}}{(1+\pi)^{2}}$ & $\frac{w^{*}}{1+\pi}$ & $w^{*}$ \\
\hline
\end{tabular}

In the face of this non-smooth path of income, households exchange bonds to smooth their consumption ${ }^{8}$, and all households consume the same amount in every period

$$
c^{*}=\frac{1}{N} \sum_{i=0}^{N-1} \frac{w^{*} n^{i *}}{(1+\pi)^{i}}
$$

where $n^{i}$ is the labour supplied by a typical household in the $i$ th period of its contract. The equation for the aggregate wage index (13) implies that when households can reset their nominal wage they choose it so that its real value is

$$
w^{*}=\left(\frac{1}{N} \frac{1-\pi^{N(\theta-1)}}{1-\pi^{\theta-1}}\right)^{\frac{1}{\theta-1}}
$$

\footnotetext{
${ }^{8}$ We show that bond market clears in Appendix B of the working paper version, available from the corresponding author's website.
} 
Combining (16) and (19) then using the government's budget constraint (10) to eliminate transfers gives a labour supply relation ${ }^{9}$ :

$$
\sum_{i=0}^{N-1} \beta_{0: i}\left(1-n^{* i}\right)^{-\eta} n^{* i}=\frac{1}{\omega\left[1+R\left(1-\xi^{*}\right)\right]}
$$

This sets the present value of the marginal disutility of labour with respect to the wage (on the left-hand side) equal to the present value of the marginal utility of the extra consumption resulting from a higher wage (on the right-hand side). Due to consumption smoothing, the right-hand side is independent of the wage since an increase in the wage leads to an increase in consumption from (19) and thus a fall in its marginal utility which, with log utility, exactly offsets the increase in income resulting from the higher wage.

Given an inflation rate $\pi$, we can use (20) to solve for the real equivalent $w^{*}$ of the nominal reset wage. Given a level of aggregate labour, (2) then gives the path of labour across the contract period. Exploiting the symmetry between the intratemporal and intertemporal properties of the model, we can then calculate consumption $c$ from (18) and obtain the proportion of credit goods $\xi$ from (17) and the allocation between labour $n$, shopping time $n^{s}$ and leisure $l$ from (8) and (9). We then iterate on the quantity of aggregate labour until (21) is satisfied.

\section{Five channels by which inflation affects real activity}

In our model there are five channels by which the rate of inflation (equal to the rate of money growth in the steady state) affects real activity. In this section we describe each of these channels in turn.

\footnotetext{
${ }^{9}$ This expression is derived in Appendix B of the working paper version, available from the corresponding author's website.
} 


\subsection{Employment cycling}

The real wage dispersion arising from staggered contracts means that, given the form of the production function (1), firms substitute towards the labour of relatively cheap households and away from relatively expensive households. This is inefficient in the sense that for a given level of aggregate labour, the higher the degree of real wage dispersion, the lower will be the level of output. Thus real wage dispersion leads to a negative relation between the absolute value of inflation and real variables. This effect is familiar in the new Keynesian literature on optimal monetary policy. For Woodford (2003, sect 2.1, p393) cycling between different types of labour is the key distortion which leads to a stabilizing role for monetary policy.

\subsection{Labour supply smoothing}

With strictly concave preferences over leisure $(\eta>0)$, the fluctuations in hours arising from employment cycling makes households worse off. In response, they supply less labour at a given wage over the contract period. This leads to a negative relation between the absolute value of inflation and real variables.

\subsection{Discounting}

When choosing their wage, households compare the present value (over the contract period) of the marginal disutility of labour $(M D L)$ with the present value of the marginal utility of consumption $(M U C)$. Since the latter is constant due to consumption smoothing and, under positive inflation, the former is rising, an increase in the discount factor means that the $M D L$ falls by more than the $M U C$ so, other things being equal, the household will set a lower wage which means it supplies more labour.

Working through the steps in detail:

1. Households set their wage so that the present value (over the contract period) of the marginal disutility of labour with respect to the wage is equal to the present value of the marginal utility of consumption from the labour income generated by a wage change. This is the labour supply relation (21). 
2. When inflation is positive, labour supply increases over the contract period because of employment cycling and thus the $M D L$ increases over the contract period. By contrast, the $M U C$ remains constant through time, since consumption is constant, given by (19).

3. Due to discounting, future marginal utilities and disutilities receive less weight than current ones. Since the $M D L$ increases over the contract period whereas the $M U C$ remains constant, an increase in discounting reduces the present value of the $M D L$ relative to the present value of the $M U C$. In response, the household sets a lower wage that raises its labour supply, thereby raising the present value of the $M D L$ to bring the two present values back into equality. So, given inflation, as the discount rate increases, labour supply increases.

4. An increase in inflation means employment cycling gets stronger so the $M D L$ increases more over the contract period and the more the discounting effect reduces the present value of the $M D L$ relative to the present value of the $M U C$. Consequently the household sets a wage that increases its labour supply to bring the two present values back into equality. So, given discounting, as the inflation rate increases, labour supply increases.

\subsection{Shopping time}

As inflation rises, and hence the nominal interest rate rises as well, households optimally substitute away from cash and towards credit goods as given by (17). This involves direct costs in terms of shopping time given by (9). The time constraint (8) then means less time is available for market activities so this generates a negative relation between the level of inflation and real activity.

\subsection{Wedge of monetary inefficiency}

The inflation tax raises the cost of consumption of cash goods, and we define the wedge of monetary inefficiency, following Khan et al (2003) as the difference between the actual cost of consumption and the cost when the nominal interest rate is zero. From inspection of (18) this wedge is equal to $R\left(1-\xi_{t}^{*}\right)$, the product of 
the nominal interest rate and the proportion of cash goods in consumption $(1-\xi)$. In other words, steady state inflation acts as a proportional tax on consumption, with the tax rate being $R\left(1-\xi_{t}^{*}\right)$. This generates a negative relation between inflation and real activity.

\subsection{Comparison}

Table 2 compares the effects of five channels on real activity ${ }^{10}$.

Table 2: Five channels linking inflation and real activity

\begin{tabular}{|l|l|l|}
\hline & \multicolumn{2}{|c|}{$\begin{array}{c}\text { Effect on real activity } \\
\text { of an increase in } \pi\end{array}$} \\
\hline & $\pi>0$ & $\pi<0$ \\
\hline Employment cycling & $\downarrow$ & $\uparrow$ \\
\hline Labour supply smoothing & $\downarrow$ & $\uparrow$ \\
\hline Discounting & $\uparrow$ & $\uparrow$ \\
\hline Shopping time & $\downarrow$ & $\downarrow$ \\
\hline Wedge of monetary inefficiency & $\downarrow$ & $\downarrow$ \\
\hline
\end{tabular}

\section{Choice of parameters}

We choose a benchmark set of parameters, shown in table 3, to allow us to explore the determinants of the optimal inflation rate in our model. We perform sensitivity analysis to all the important parameters in section 5.3 below.

\footnotetext{
${ }^{10}$ There is a close mapping between these five channels and the model of Khan et al (2003). The key difference is that we assume sticky nominal wages, whereas Khan et al (2003) assume sticky nominal prices. The real wage dispersion in our model corresponds to "relative price distortion" in theirs: we prefer the term "employment cycling" since it focusses on the effect of inflation on quantities directly relevant for welfare, rather than prices. "Labour supply smoothing" corresponds to their "markup distortion" - in our model inflation, via household preferences, effects the markup of the real wage over the marginal disutility of labour. The discounting effect is present in their model, but is small due to their assumption of exponential discounting (for a comparison of exponential and hyperbolic discounting see Graham and Snower, 2008).
} 


\section{Table 3: Parameters}

\begin{tabular}{|l|l|l|l|l|l|l|l|}
\hline$\eta$ & $\zeta$ & $r$ & $\gamma$ & $N$ & $\theta$ & $\tau$ & $n$ \\
\hline 1 & 2.3 & 0.04 & 0.7 & 12 & 5 & 0.35 & 0.2 \\
\hline
\end{tabular}

\subsection{Wage setting}

We take the length of a contract to be one year, following Taylor (1999), and assume it remains constant as inflation varies. We discuss the empirical rationale for this in section 6.2 .

\subsection{Period of Analysis}

In our model the period of analysis is important for two reasons. Firstly, it determines the time over which the high short-run discount factor applies and so the strength of the discounting effect - this is discussed in the next subsection Secondly, it affects average money balances and so the importance of the inflation tax. We choose a period of analysis of one month, and this, along with our assumption of a contract length of one year implies that there are twelve wage setting cohorts $N=12$.

\subsection{Preferences}

We have already restricted household's utility functions (4) to be separable in consumption and leisure implying logarithmic preferences over consumption, and we further choose logarithmic preferences over leisure, $\eta=1$. The weight on leisure in the utility function, $\zeta$, is chosen so that households spend $20 \%$ of their time working (standard in the RBC literature).

In appendix A.8 we show that the three time preference parameters $\delta, \gamma$ and $r$ are related by

$$
\delta=\frac{1}{1+\gamma r}
$$

so given our calibration of the real interest rate we only need to pick one of the discounting parameters.

The choice of $\gamma$, the parameter measuring the size of short-run subjective discounting, is more difficult. Values of between $60 \%$ and $70 \%$ are standard in the 
hyperbolic discounting literature, for example Laibson et al (2007), but applying to annual data. There are some attempts to estimate quasi-hyperbolic discount functions over shorter time horizons, all using the pattern of consumption between paydays. Shapiro (2005) finds a daily discount factor of around 90\%; Huffman and Barenstein (2005) find a range from $87 \%$ to $97 \%$; Mastrobuoni and Weinberg (2009) obtain broadly similar results. Note that these studies are incompatible with Laibson's work since they imply an annual discount factor much higher than 70\%. There are also a number of serious methodological issues in comparing different studies ${ }^{11}$.

The only survey we are aware of is Fredrick et al (2002). Their findings on the short-run discount factor, in their table 1a, suggest that it is somewhere between $0 \%$ and $80 \%$. Given the lack of a consensus, we choose $\gamma=70 \%$ for our baseline calibration. This choices implies via (22) a value for the long-run discount parameter $\delta$ of 0.998 . So our calibration is broadly compatible with Laibson's since our annual discount factor will be $\gamma \delta^{11} \approx 68 \%$.

A further choice is whether the period of analysis should be the same as the period over which the high short-run discount factor applies. Making the period of analysis longer than the period of high discounting would have no great effect. Making it shorter would involve an extra parameter and would require assumptions about how to "compound down" the short-run discount factor. In the absence of any empirical guidance on these issues we choose to keep the period of analysis the same as the period over which the short-run discount factor applies i.e. the "kink" in the quasi-hyperbolic discount function is after one period.

\subsection{Money demand}

Demand for real balances in our model is given by $m_{t}=\left(1-\xi_{t}\right) c_{t}$ and $\xi$, the proportion of credit goods, depends on the distribution of costs via (17). Since we take our model of credit goods from Khan et al (2003), we can also use their

\footnotetext{
${ }^{11}$ One issue is that discounting would be expected to vary across groups in society. Since the differenst studies use different data sets, they may be measuring the discounting of different groups. In the current paper we describe the behaviour of wage setters who will be present in different data sets to different extents. Another issue is that discounting parameters are estimated jointly with the intertemporal elastically of consumption and also depend on other assumptions such as the extent of credit constraints.
} 
estimates for the form of the cost distribution function $F$. They posit that $F$ has a generalized beta distribution

$$
F(x)=\xi_{L}+\xi_{H} B\left(\frac{x}{\kappa} ; b_{1}, b_{2}\right)
$$

where $B$ is the beta distribution, and then use US data to estimate the five parameters, $\xi_{L}, \xi_{H}, \kappa, b_{1}, b_{2}$, based on two data sets, a "short sample" starting in 1959 and a "long sample" starting in $1948^{12}$. For our benchmark calibration, we use the short sample estimates and report results for the long sample estimates in our sensitivities section.

\subsection{Other parameters}

For the elasticity of labour substitution, $\theta$, we choose a value of $5{ }^{13}$ We set the level of labour taxation $\tau$ to be $35 \%$, corresponding roughly to the average for the OECD, see Mendoza et al (1994).

\subsection{The zero-inflation steady state}

At zero inflation, there are no relative price distortions since the real wage is constant over the contract period. Given the above choice of parameters, households buy $65 \%$ of goods with credit, and hence the ratio of money balances to consumption is $35 \%$. Households spend $0.003 \%$ of their time endowment shopping. This is similar to the value in Khan et al (2003) and is consonant with the observation by Lucas (2000) that households spend "several hours per year" avoiding the inflation tax.

\section{The optimal rate of inflation}

Optimal monetary policy in the long run involves choosing a steady state inflation rate (money growth rate) to maximize social welfare. However defining social welfare is not straightforward since with time-inconsistent preferences, different

\footnotetext{
${ }^{12}$ Details are in Khan et al (2003) footnote 22

${ }^{13}$ Erceg et al (2000) use a value of 4; Huang and Liu (2002) use 6.
} 
selves will not necessarily agree on rankings of utility flows (see İmrohoroğlu et al., 2003). One approach is to define social welfare as a sum of the utility of all selves at all points in time, choosing a backward discount factor to measure how a self at some particular time values utility flows at earlier times. The choice of a backward discount factor is complex (see İmrohoroğlu et al., 2003 and Caplin and Leahy, 2004) but assuming it is between 0 and 1 (i.e. utility in the past is valued less than utility today) Appendix B.4 shows that the social welfare function, defined as the sum of the utility of all $N$ selves in all $N$ contracts is proportional to

$$
S W=\sum_{i=0}^{N-1} u\left(c^{i}, l^{i}\right)
$$

where the constant of proportionality is a function of the backward discount factor and the steady state rate of interest i.e. it is independent of all the parameters we will vary.

Output and hence consumption in the zero-inflation steady state are below the first best due to the presence of distorting labour taxes and imperfect competition. This means that if there is a positive trade off between real variables and inflation at least in some range from zero inflation upwards, the monetary policymaker can potentially improve social welfare by choosing higher inflation.

Given our choice of parameters, the annual inflation rate that maximizes social welfare is $2.1 \%$. In the next two sections we explain the role of the five channels in this result, and show how it depends on our choice of parameters.

\subsection{Selectively removing channels}

How much do each of the five channels by which inflation affects real variables (described in section 3) contribute to our benchmark result? Table 4 reports the effect of selectively eliminating combinations of the channels ${ }^{14}$.

\footnotetext{
${ }^{14}$ We eliminate the discount effect by setting $\beta_{t: t+i}=1$ for all $t, i$; labour supply smoothing by setting $\eta=0$; the wedge by setting $R(1-\xi)$ to zero in the labour supply equation; shopping time by forcing $n_{t}^{s}=0$; employment cycling by forcing $n$ to be constant over the contract period at its calibrated value.
} 
Table 4: Selectively removing channels

\begin{tabular}{|l|l|}
\hline & $\begin{array}{c}\text { Optimal } \\
\text { inflation }\end{array}$ \\
\hline Benchmark result & $2.1 \%$ \\
\hline Eliminate & \\
\hline 1. Discounting & $-1.3 \%$ \\
\hline 2. Discounting, shopping time & $-0.88 \%$ \\
\hline 3. Discounting, wedge & $-0.55 \%$ \\
\hline 4. Discounting, shopping time, wedge & $0.0 \%$ \\
\hline 5. Discounting, employment cycling, labour supply smoothing & $-3.9 \%$ \\
\hline
\end{tabular}

Discounting is the only one of the five channels which leads to a positive relation between inflation and real activity, and eliminating it means that deflation becomes optimal. This mirrors the result of Khan et al (2003) that, in the absence of discounting, the other channels imply that mild deflation is optimal (Khan et al's, 2003 equivalent optimal rate is $-0.76 \%$ ).

Shopping time and the wedge of monetary inefficiency represent the effects of the inflation tax in terms of shopping time and the cost of consumption respectively. Eliminating either of these therefore will raise the optimal inflation rate, and lines 2 and 3 of the table show this. If both of these effects and discounting are eliminated, the only channels that remain are employment cycling and labour supply smoothing. Both of these imply a negative relation between the absolute value of inflation and real variables: hence taken on their own they imply that zero inflation is optimal, line 4 of the table.

If we eliminate the effects of relative price instability by "switching off" employment cycling, the only effects of inflation would be shopping time and the wedge of monetary inefficiency. Setting the nominal interest rate to zero eliminates both of these (as can be seen from inspection of (17) and (21)) so the Friedman rule is optimal. With $R=0$, the Fisher relation implies $1+\pi=(1+r)^{-1}$ and given our choice of $r=4 \%$ this means $\pi=-3.9 \%$ 


\subsection{Monetary policy and inefficiency}

The level of optimal inflation will depend on the degree to which the steady state is inefficient. In our model the zero-inflation steady state is inefficient due to imperfect competition in the labour market and the tax on labour income and we can demonstrate the following striking result: the greater the inefficiency in our economy - so that the lower is steady-state output relative to optimal output - then the greater is the optimal inflation rate. In short, the optimal inflation rate is not independent of the degree of economic inefficiency. On the contrary, the optimal inflation rate is positive because it can compensate for an inefficient steady state level of real activity.

The degree of imperfect competition is given by the parameter $\theta$ which represents the level of market power of a particular labour type. From (1), the higher is $\theta$, the more substitutable are labour types, so the lower is market power. If we weaken the degree of imperfect competition by raising $\theta$ from the baseline of 5 to a value of 7 , the optimal rate of inflation falls to $1.8 \%$. Similarly, if we increase the degree of imperfect competition by choosing $\theta=3$, the optimal rate of inflation increases to $2.3 \%$.

The proportional labour income tax is a rate $\tau$, chosen to be $35 \%$ in our baseline calibration. Reducing the tax rate to $25 \%$, thus making the steady state less inefficient reduces the optimal rate of inflation to $1.7 \%$. Increasing the tax rate to $45 \%$ increases the optimal inflation rate to $2.6 \%$.

This result has wide-ranging implications and we discuss some of these in section 6.3 below.

\subsection{Sensitivity analysis}

In this section we describe how variations in other model parameters affect the optimal rate of inflation. Although there is a large degree of uncertainty about many of the parameters of our model, this section shows that our main result, that a positive rate of inflation is optimal, is robust to variations in our benchmark calibration. 


\subsubsection{Discounting and period of analysis}

Table 5 shows how the optimal rate of inflation varies with these the short-run discount factor and the period of analysis ${ }^{15}$. We choose short-run discount factors ranging from $60 \%$ to $95 \%$, and a period of analysis from semi-annual to weekly (semi-annual contracts are the longest that are compatible with overlapping wage contracts a year in length). Looking along the rows we see that the higher the short-run discount factor, the greater the optimal rate of inflation. In order for optimal inflation to be positive when equilibrium output is inefficiently low, there must be a positive relation between inflation and real economic activity. The only channel in our model which leads to such a positive relation is discounting. The more heavily households discount the short-term future, the greater the positive effect of inflation on real economic activity and thus the greater is the optimal inflation rate. Note that the macroeconomic literature on hyperbolic discounting typically uses values in the first three columns of the table.

Table 5: Sensitivity to discount factor and period of analysis

\begin{tabular}{|l|l|l|l|l|l|}
\hline$N \backslash \gamma$ & 0.6 & 0.7 & 0.8 & 0.9 & 0.95 \\
\hline 52 & $1.4 \%$ & $1.0 \%$ & $0.74 \%$ & $0.56 \%$ & $0.47 \%$ \\
\hline 12 & $3.7 \%$ & $\mathbf{2 . 1} \%$ & $0.92 \%$ & $-0.02 \%$ & $-0.41 \%$ \\
\hline 4 & $8.8 \%$ & $5.6 \%$ & $2.8 \%$ & $-1.9 \%$ & $-2.8 \%$ \\
\hline 2 & $10 \%$ & $6.8 \%$ & $2.2 . \%$ & $-3.9 \%$ & $-3.9 \%$ \\
\hline
\end{tabular}

Our baseline calibration takes the period of analysis to be a month. In standard models, the period of analysis has small effects, if any. In contrast, in our model the period has two offsetting effects. Firstly, the longer the period of analysis, the greater the real money balances that households hold, other things being equal, and thus the greater is the effect of the inflation tax and the lower is the optimal rate of inflation. Secondly, the period of analysis is also the length of time for which the high short-run discount rate applies and tends to strengthen the discounting effect and thus raises the optimal rate of inflation. The table shows that the first effect dominates when discounting is weak; and the second when discounting is strong.

\footnotetext{
${ }^{15}$ When we change the short-run discount factor we also need to change the long-run discount factor according to $(22)$ to keep the real interest rate at its calibrated value.
} 


\subsubsection{Shopping Time}

The properties of shopping time and the monetary wedge are largely determined by the estimates of the shopping time function which we take from Khan et al (2003). They present two sets of estimates, one based on a short sample period and the other on a longer sample. In our base calibration we use the former. If instead we use the latter, the optimal inflation rate becomes $2.6 \%$. Although the optimal rate doesn't change much, the relative magnitude of the effects of the monetary wedge and shopping time changes considerably. ${ }^{16}$

\subsubsection{Labour supply elasticity}

As the elasticity of labour supply falls ( $\eta$ increases), households become more averse to non-smooth paths of labour so the positive trade-off between output and inflation weakens and optimal rate of inflation falls. This effect is shown in table $6^{17}$.

Table 6: Sensitivity to labour supply elasticity

\begin{tabular}{|l|l|l|l|l|l|}
\hline$\eta$ & 0 & 1 & 2 & 5 & 10 \\
\hline & $6.7 \%$ & $2.1 \%$ & $1.4 \%$ & $0.72 \%$ & $0.45 \%$ \\
\hline
\end{tabular}

\subsubsection{Summary}

As discussed in section 4, there is a large degree of uncertainty over all the important parameters of the model, both in terms of their measurement and of mapping what is a very stylised model onto the world. However this section has shown that our result of a positive optimal rate of inflation is robust to plausible variations in the parameters with the exception of the discount factor. This reemphasizes the importance of discounting as the only channel which leads to a positive relation between inflation and real variables.

\footnotetext{
${ }^{16}$ In our baseline calibration, shopping time increases by $1.9 \%$ from its value at zero inflation to its value at the optimal rate, and the proportion of credit goods by $0.02 \%$. Using the "long sample" estimates of money demand, these values become $0.15 \%$ and $0.13 \%$ respectively.

${ }^{17}$ The table includes the limiting case $\eta=0$.This corresponds to the case of "indivisible labour" (Hansen, 1985) in the RBC literature but the justification for this is based on a lottery among heterogenous agents. Such a justification is not valid in our model since we would expect the outcome of such a lottery to be different under hyperbolic discounting.
} 


\section{Discussion}

\subsection{Calvo contracts}

Calvo contracts are common in standard new Keynesian models which are linearized around a zero inflation rate. However they give anomalous results in models with non-zero steady state inflation. The problem is as follows. Calvo contracts imply that, if there are a large number of households, some of them never reset their nominal wage. With positive steady state inflation, this means the real wage of such households falls to zero. Given the simple CES form of firms' production function (1), firms substitute completely to these wage setters meaning production falls towards zero. Bakshi et al (2003) address this issue more formally and show that Calvo contracts imply a maximum rate of steady state inflation that can be analyzed - given their calibration, this maximum value is $5.5 \%$ - and that they distort the steady state for any value of inflation substantially different from zero.

\subsection{The absence of indexation}

A key assumption of our analysis are that wages are set annually in nominal terms, and that within this contract period of one year there is no indexation. In this assumption we follow Khan et al (2003) who specify a more complex process of price adjustment than us but still assume that it is exogenous. In this section we review the evidence for this.

When thinking about the nature of wage contracts it is important to distinguish between unionized and non-unionized workers. Taylor (1999), reviewing the direct empirical evidence for the unionized sector in the US, cites a large number of studies that suggests that annual contracts are the most common length of wage setting interval. The wide variation across countries is captured by Groth and Johansson (2004) who update the study of Bruno and Sachs (1985) with data from 1985 - 1995. They assign countries an index which takes a value of 0 if the average length of union contract is a year or less, 1 if it is from $1-3$ years and 2 if it is greater than 3 years. The mean of this index across OECD countries was 0.94 for 1985 - 1995, suggesting a mean contract length greater than a year. 
There is much less evidence on the non-unionized sector, partly because the most common source of data are panel data sets (the PSID for the US, or the BHPS for the UK) which typically collect their data annually so necessarily miss any sub-annual wage setting. However there does seem to be a consensus in the literature that most wages are set annually. For example, for the US, Taylor (1999) writes, "setting nominal wages at a fixed level for more than several quarters and usually for as long as a year appears to be just as prevalent for workers who are not in unions, or do not have formal employment contracts, as for union workers with employment contracts". Smith (2000), referring to the UK, notes that "pay negotiation in the United Kingdom typically occur at annual intervals, and pay awards are often made every 12 months even for workers who are not covered by collective bargaining" and Brown et al (2004) state that the annual wage settlement is "the principal source of pay change for most employees in Britain". This is consonant with estimates of the degree of wage stickiness (reviewed in Taylor, 1999) using aggregate data which typically find the average length of time between wage changes to be greater than one year.

Because we assume the length of nominal contracts is fixed at one year while we vary inflation, our model is subject to a version of the Lucas critique. Wouldn't agents change their wage setting behaviour as steady state inflation varies? So an important empirical question is the degree to which the contract period changes with steady state inflation. Taylor (1999) writes that the average contract period fell to one year (our baseline value) during the great inflation of the 1970s, when average inflation was well above the range we consider in this paper. Looking across the OECD, Groth and Johansson (2004) find their index variable was 0.78 in the period 1975 - 85, still consistent with an average contract length above a year, and rose to 0.94 in the next ten years when average inflation was lower. So this suggests that modelling nominal contracts as fixed at one year over a range of inflation from $0-10 \%$ as we do in this paper is, if anything, a conservative assumption and we could expect contracts to be longer now that average inflation is low.

Our assumption of Taylor contracts, without intra-contract indexation, instead of Fisher contracts, is similarly open to the Lucas critique. First note that our model of annual nominal contracts nests annual indexation since wages are opti- 
mally reset each year. Only indexation within the annual contract period would affect our results. The empirical evidence on indexation is striking. Card (1986), writing about a period when average inflation was well over the top of the range we consider, notes that "perhaps no more than $10 \%$ of all US workers are covered by cost-of-living provisions". This surprising result arises because indexation is only observed in union contracts and, as Card (1983) reports, only in around 60\% of these, and "escalation provisions are rare in the non-union sector". Further, while one can find evidence of quarterly cost of living (COLA) adjustments, the vast majority seem to be annual (Kaufman and Woglom, 1986, Vroman, 1985). More recently, Christofides and Leung (2003), looking at Canadian data from 1976 - 1999, write that "very few contracts contain COLA clauses". So while wage indexation is a feature of very high inflation rates (Marinakis, 1997), it seems largely absent over the range of inflation we consider.

\subsection{Monetary policymaking}

While our model is very stylized, an implication of our analysis is that the structure of the economy - insofar as it affects the degree of economic inefficiency - should be a factor that influences policymakers' choice of an inflation target. At present, inflation targets are chosen to be around $2 \%$ largely on the grounds that such a rate is consistent with price stability (in the sense that inflation of around $2 \%$ has little adverse impact on agents' decisions) and it is sufficiently positive to avoid the nominal rate hitting the zero-lower bound too often. However our analysis suggests that the structure of the economy should also be taken into account when choosing an inflation target. Specifically, the more inefficient is equilibrium output and employment, the higher the inflation target should be. This implies that inflation targets should be re-evaluated over time as the structure of the real economy changes. It also has obvious implications for the analysis of optimum currency areas. Different countries in a currency union will in general have different degrees of steady-state inefficiency, so the mechanism in this paper gives a new source of differential welfare effects across countries in addition to those discussed in, for example, Benigno (2004).

We most certainly do not wish to argue that monetary policy should always 
compensate for inefficiencies in labour and product markets. Usually policy makers can deal with these inefficiencies more effectively through the use of structural and fiscal policies, e.g. policies that promote competition in product and labour markets, structural policies that reduce institutional rigidities, taxes and subsidies that overcome market failures in these markets. The reason is that the latter policies may reduce the inefficiencies at lower cost than monetary policy. But for any given level of inefficiency that remains once fiscal and structural policies are at their optimal levels, monetary policy should not ignore the inefficiencies that remain.

\section{Conclusion}

We have shown that the interaction between nominal contracts and hyperbolic discounting can lead to a tradeoff between inflation and macroeconomic activity for which a small positive inflation rate is optimal. In our baseline calibration, this rate is $2.1 \%$ and remains positive for a wide range of calibrations. Our analysis is meant to narrow the gulf between monetary theory and practice. Thus far, monetary theory has suggested that the optimal inflation rate is negative beginning with the Friedman rule and ranging to the more moderate, but still negative optimal inflation of Khan et al. (2003) - but central bankers have never taken this seriously. Our analysis is a first step in reconciling the optimal inflation literature with the practice of targeting small positive inflation rates.

The optimal inflation rate in our model is a result of the relative magnitudes of five channels by which inflation affects real activity, and we have analyzed the effects of these channels in our model: shopping time, the wedge of monetary inefficiency, employment cycling, labour supply smoothing and discounting.

A general implication of our analysis is that the optimal rate of inflation depends on the structure of the economy in two ways. Firstly via the degree of structural inefficiency. We show that as the equilibrium becomes more inefficient, due to higher labour taxes or more imperfect competition, the optimal inflation rate rises. Secondly, via the mechanisms by which inflation affects real variables. An important topic for further research would be to examine a variety of different common inefficiencies and examine whether they have similar implications for 
monetary policy.

\section{References}

Amano, Robert and Kevin Moran, (2008), "Trend Inflation and Economic Growth in the Presence of Nominal Price Contracts", Unpublished

Ascari, Guido, (1998), "Superneutrality of money in staggered wage-setting models", Macroeconomic Dynamics 2, pp.383-400.

Bakhshi, Hasan, Pablo Burriel-Llombart, Hashmat Khan and Barbara Rudolf, (2003), "Endogenous price stickiness, trend inflation, and the New Keynesian Phillips curve", Bank of England Working Paper 191.

Barro, Robert J, (1999), "Ramsey Meets Laibson In The Neoclassical Growth Model", Quarterly Journal of Economics 114 (4), pp.1125-1152.

Benigno, Pierpaolo, (2004), "Optimal monetary policy in a currency area," Journal of International Economics,63(2), pp. 293-320.

Billi, Roberto M. \& George A. Khan, 2008, "What is the optimal inflation rate?," Economic Review, Federal Reserve Bank of Kansas City, issue Q II, pages 5-28.

Brown, Donna, Peter Ingram and Jonathan Wadsworth, (2004). "Everyone's A Winner? Union Effects on Persistence in Private Sector Wage Settlements: Longitudinal Evidence from Britain," Department of Economics Discussion Papers 1104, Department of Economics, University of Surrey

Bruno, M and Jeffery D Sachs, (1985), "The economics of worldwide stagflation", Blackwell, Oxford.

Caplin, Andrew \& John Leahy, 2004. "The Social Discount Rate," Journal of Political Economy, University of Chicago Press, vol. 112(6), pages 1257-1268, December.

Card, David (1983), "Cost of living escalators in major union contracts", Industrial and Labour Relations Review, 37, pp. 34 - 48 
Card, David, (1986), "An Empirical Model of Wage Indexation Provisions in Union Contracts," Journal of Political Economy, vol. 94(3

Christofides, Louis N. and Man Tuen Leung, (2003), "Nominal Wage Rigidity in Contract Data: A Parametric Approach," Economica, vol. 70(280), pages 619-638

Dixit, Avinash K and Joseph E Stiglitz, (1977), "Monopolistic Competition and optimum product diversity", American Economic Review 67 (3), pp.297-308.

Erceg, Christopher J, Dale W Henderson and Andrew T Levin, (2000), "Optimal monetary policy with staggered wage and price contracts", Journal of Monetary Economics 46, pp.281-313.

Fredrick, Shane, George Loewenstein and Ted O'Donoghue (2002) “Time Discounting and Time Preference: A Critical Review," Journal of Economic Literature, June, 40, 351-401.

Gomme, Paul, (1993), "Money and growth revisited. Measuring the costs of inflation in an endogenous growth model," Journal of Monetary Economics 32: 51-77.

Graham, Liam and Dennis J Snower, (2004), "The real effects of money growth in dynamic general equilibrium", European Central Bank Working Paper No 412

Graham, Liam and Dennis J Snower, (2008),"Hyperbolic discounting and the Phillips curve", Journal of Money, Credit and Banking, Vol. 40, No. 2-3.

Groth, Charlotta and Asa Johansson, (2004). "Bargaining structure and nominal wage flexibility," European Economic Review, Elsevier, vol. 48(6), pp. 1349-1365. Hansen, G.D., (1985), Indivisible labour and the business cycle. Journal of Monetary Economics, vol. 16(3), pages 309-327, November.

Huang, Kevin XD and Zheng Liu, (2002), "Staggered price setting, staggered wage setting and business cycle persistence", Journal of Monetary Economics 49, pp.405-433.

Huffman , David and Matias Barenstein (2005), "A Monthly Struggle for SelfControl? Hyperbolic Discounting, Mental Accounting, and the Fall in Consumption Between Paydays", IZA DP 1430. 
İmrohoroğlu, Ayse, Selahattin İmrohoroğlu, and Douglas H. Joines, (2003), "Timeinconsistent preferences and social security". Quarterly Journal of Economics, 118(2), pp. $745-784$

Kaufman, Roger T and Geoffrey Woglom (1986), "The Degree of Indexation in Major U.S. Union Contracts", Industrial and Labor Relations Review, Vol. 39, No. 3. (Apr., 1986)

Khan, Aubhik Robert G. King; Alexander L. Wolman, (2003), "Optimal monetary policy", Review of Economic Studies,10, 4 , pp 825-860

Laibson, David (1996), "Hyperbolic Discount Functions, Undersaving, and Savings Policy", NBER Working Papers 5635.

Laibson, David (1997), "Golden Eggs and Hyperbolic Discounting", Quarterly Journal of Economics, Vol. 112, No. 2, pp. 443-477

Laibson, David, Andrea Repetto, Jeremy Tobacman (2007), "Estimating Discount Functions with Consumption Choices over the Lifecycle", NBER Working Paper 13314

Levin, Andrew and Tack Yun, (2007), "Reconsidering the natural rate hypothesis in a New Keynesian framework", Journal of Monetary Economics , 54, 5, pp 13441365

Lucas, R.E. Jr, (2000), "Inflation and Welfare", Econometrica, 68 (2), 247-274.

Marinakis, Andrés E (1997), "Wage policy in high inflation countries: The role of indexation in Latin America during the 1980s", Journal of Economic Studies, 24 (6) pp. 356 - 378.

Mastrobuoni, Giovanni and Matthew Weinberg, (2009), "Heterogeneity in Intramonthly Consumption Patterns, Self-Control, and Savings at Retirement," American Economic Journal: Economic Polic1(2), pp 163-89.

Mendoza, Enrique G. Razin, Assaf and Tesar, Linda L., (1994), "Effective tax rates in macroeconomics: Cross-country estimates of tax rates on factor incomes 
and consumption," Journal of Monetary Economics, Elsevier, vol. 34(3), pages 297-323.

Romer, David, (1990), "Staggered price setting with endogenous frequency of adjustment", Economics LettersVolume 32, 3, pp. 205-210.

Shapiro, Jesse (2005) "Is There a Daily Discount Rate? Evidence from the Food Stamp Nutrition Cycle," Journal of Public Economics, Feb., 89(2-3), 303-325.

Sinclair, Peter J. N., (2003), "The Optimal Rate of Inflation: An Academic Perspective". Bank of England Quarterly Bulletin

Smith, Jennifer C, (2000), "Nominal Wage Rigidity in the United Kingdom," Economic Journal, vol. 110(462), pp. C176-95

Taylor, John, (1979), "Staggered Wage Setting in a Macro Model", American Economic Review 69 (2), pp.108-113.

Taylor, John, (1999), "Staggered price and wage setting in macroeconomics", in John. B. Taylor and Michael Woodford (ed.), (1999), "Handbook of Macroeconomics", chapter 15, pp. 1009-1050.

Vroman, Wayne (1985), "Cost-of-Living Escalators and Price-Wage Linkages in the U.S. Economy,1968-1980", Industrial and Labor Relations Review, Vol. 38, No. 2., pp. 225-235.

Woodford, Michael, (2003), "Interest and prices", Princeton University Press, Princeton 


\section{A Solving the household's problem}

Under hyperbolic discounting, the household's preferences are time inconsistent so standard dynamic programming techniques cannot be used. Instead, we model the household at time $t$ as playing a game against its future selves. Throughout this appendix we are considering the problem of a single household so drop the $(h)$ notation for brevity.

\section{A.1 Preliminaries}

\section{A.1.1 Utility function}

Household utility (4) is defined in terms of consumption $c_{t}$ and leisure $l_{t}$. However leisure is determined by (i) the proportion of credit goods $\xi_{t}$ and (ii) the wage $w_{t}$ which determines the firm's labour demand. Use the time constraint (8) and the expressions for labour demand (2) and shopping time (9) to write leisure in terms of the choice variables

$$
l_{t}=1-w_{t}^{-\theta} y_{t}-\int_{0}^{F^{-1}\left(\xi_{t}\right)} \varpi d F(\varpi)
$$

and use this to rewrite the utility function in terms of the choice variables (recall that $y_{t}$ is exogenous to the household's problem):

$$
v\left(c_{t}, w_{t}, \xi_{t}\right)=\log c_{t}+\frac{\zeta}{1-\eta}\left\{1-w_{t}^{-\theta} y_{t}-\int_{0}^{F^{-1}\left(\xi_{t}\right)} \varpi d F(\varpi)\right\}^{1-\eta}
$$

\section{A.1.2 Net assets}

It will prove helpful to define the consumption function in terms of net assets. This section reconciles this approach with the budget constraint (5), reproduced here:

$$
m_{t}+\frac{1}{1+R} b_{t+1}=\frac{b_{t}-d_{t}}{1+\pi}+(1-\tau) w_{t} n_{t}+\chi_{t}
$$


1. Substitute for money and credit from (6) then subtract $d_{t+1}$ from both sides using (7) to obtain

$$
b_{t+1}-d_{t+1}=(1+r)\left(b_{t}-d_{t}\right)+(1+R)\left[(1-\tau) w_{t} n_{t}+\chi_{t}\right]-(1+R)\left(1-\xi_{t}\right) c_{t}-\xi_{t} c_{t}
$$

2. Define net assets as net bonds less credit, $a_{t}=b_{t}-d_{t}$

3. Assume at the start of time the household sells its lifetime income (which consists of labour income, transfers and the initial redistribution of wealth which is equivalent to spreading the household's income equally over the contract period ${ }^{18}$ ) in exchange for bonds:

$$
a_{0}=\sum_{j=0}^{m-1} \frac{1}{(1+r)^{m N}} z_{j}
$$

where $z_{j}$ is the discounted value of average contract income in the contract period starting in $t=j N$

$$
z_{j}=\frac{\varphi}{N} \sum_{t=j N}^{(j+1) N-1}\left[(1-\tau) w_{t} n_{t}+\chi_{t}\right]
$$

and $\varphi=\frac{1-(1+r)^{-N}}{1-(1+r)^{-1}}$.

4. Then assets evolve according to

$$
a_{t+1}=(1+r) a_{t}-(1+R)\left(1-\xi_{t}\right) c_{t}-\xi_{t} c_{t}
$$

\section{A.2 The household's problem}

Consider a game of length $m N$ where $m$ is an integer. Time runs from at $T=0$ to $T=m N-1$ and wages are set in periods $0, N, 2 N \ldots(m-1) N$. The household's

\footnotetext{
${ }^{18}$ This is necessary to ensure that in the steady state households in all cohorts have the same lifetime wealth. For full details see Appendix B of the working paper version, available from the corresponding author's website.
} 
value function is

$$
V\left(a_{t}, w_{t}\right)=\max \left[v\left(c_{t}, w_{t}, \xi_{t}\right)+\gamma \delta V\left(a_{t+1}, w_{t+1}\right)\right] ; 0 \leq t \leq T
$$

subject to asset evolution (A.6). $v$ is as defined in (A.2).

Continuation utility is

$$
V\left(a_{t+1}, w_{t+1}\right)=\sum_{i=1}^{T-t} \delta^{i-1} v\left(c_{t+i}, \xi_{t+i}, w_{t+i}\right)
$$

Note:

1. Time inconsistency means that actual utility from the perspective of the household at time $t+1$ will be different from continuation utility since a different discount factor will be applied to the utility flows. This is why standard dynamic programming techniques cannot be used.

2. Wages are set every $N$ periods so $w_{t}$ is in general the wage prevailing at time $t$ and not necessarily a choice variable in that period.

3. We do not allow the use of credit in the final period of the game.

The optimum strategy is found by backwards induction. The problem is first solved in the final period $T$, then in a general period $0 \leq t<T$.

\section{A.3 The final period, $t=T$}

In the final period we assume credit goods cannot be used (since the credit would never be repaid) so $\xi_{m N-1}=0$ and the household simply consumes the value of the remaining assets, which from (A.6) is

$$
c_{T}=\frac{1+r}{1+R} a_{T}=\lambda_{T} a_{T}
$$

where $\lambda_{T}=\frac{1}{1+\pi}$. 


\section{A.4 Other periods $0 \leq t<T$}

The first-order conditions of the maximization problem given by (A.7) with respect to $c_{t}, \xi_{t}$ and $w_{t}$ are

$$
\begin{aligned}
& v_{c}=-\gamma \delta V_{a} \frac{d a_{t+1}}{d c_{t}} ; 0 \leq t<m N-1 \\
& v_{\xi}=-\gamma \delta V_{a} \frac{d a_{t+1}}{d \xi_{t}} ; 0 \leq t<m N-1 \\
& v_{w}=-\gamma \delta\left(V_{a} \frac{d a_{t+1}}{d w_{t}}+V_{w}\right) ; t=n N, n \in \mathbb{Z}, 0 \leq n<m,
\end{aligned}
$$

The first equation sets the marginal utility of consumption equal to its cost of in terms of reduced future utility. The second sets the marginal disutility of an increase in the proportion of credit goods (in terms of higher shopping time and hence reduced leisure) equal to the benefit in terms of higher future consumption. The third sets the marginal benefit of setting a higher wage (in terms of increased leisure in the current period) against the future marginal costs in terms of reduced future consumption $\left(V_{a} \frac{d a_{t+1}}{d w_{t}}\right)$ and reduced future leisure $\left(V_{w}\right)$. Recall that since wage are only set every $N$ periods the first-order condition for the wage is only valid for $t=0, N, 2 N \ldots$

\section{A.5 The strategy for consumption}

Using the utility function (A.2)

$$
v_{c}=\frac{1}{c_{t}}
$$

Conjecture that the optimal strategy for consumption is of the form

$$
c_{t}=\lambda_{t} a_{t}
$$

Differentiate the asset evolution equation (A.6) to give

$$
\frac{d a_{t+1}}{d c_{t}}=-\left(1+R\left(1-\xi_{t}\right)\right)
$$


Combine these with the first-order condition for consumption (A.10) to give

$$
\frac{1}{c_{t}}=\gamma \delta\left(1+R\left(1-\xi_{t}\right)\right) V_{a}
$$

Differentiating continuation utility (A.8) and using (A.14)

$$
V_{a}=\sum_{i=1}^{T-t} \delta^{i-1} \frac{\lambda_{t+i}}{c_{t+i}} \frac{d a_{t+i}}{d a_{t+1}}
$$

The asset evolution equation (A.6) can be written

$$
a_{t+1}=\mu_{t} a_{t}
$$

where

$$
\mu_{t}=(1+r)-\left[1+R\left(1-\xi_{t}\right)\right] \lambda_{t}
$$

so

$$
a_{t+i}=\prod_{j=1}^{i-1} \mu_{t+j} a_{t+1} ; i>1
$$

then

$$
\frac{d a_{t+i}}{d a_{t+1}}=\prod_{j=0}^{i-1} \mu_{t+j}=\frac{a_{t+i}}{a_{t+1}}
$$

Substituting this into (A.17)

$$
\begin{aligned}
V_{a} & =\sum_{i=1}^{T-t} \delta^{i-1} \frac{\lambda_{t+i}}{c_{t+i}} \frac{a_{t+i}}{a_{t+1}} \\
& =\sum_{i=1}^{T-t} \delta^{i-1} \frac{1}{a_{t+i}} \frac{a_{t+i}}{a_{t+1}} \\
& =\frac{1}{a_{t+1}} \sum_{i=1}^{T-t} \delta^{i-1} \\
& =\frac{1}{\mu_{t} a_{t}} \frac{1-\delta^{T-t-1}}{1-\delta}
\end{aligned}
$$

where the first step uses (A.14) and the third uses (A.18). 
So (A.16) becomes

$$
\frac{1}{c_{t}}=\frac{1+R\left(1-\xi_{t}\right)}{\Theta \mu_{t} a_{t}}
$$

where $\Theta=\frac{1-\delta}{\gamma \delta\left(1-\delta^{T-t-1}\right)}$

Then using (A.14)

$$
\lambda_{t}=\frac{\Theta \mu_{t}}{1+R\left(1-\xi_{t}\right)}
$$

and using (A.19)

$$
\lambda_{t}=\frac{\Theta}{1+\Theta} \frac{1+r}{1+R\left(1-\xi_{t}\right)}
$$

\section{A.6 The strategy for the proportion of credit goods}

Using the utility function (A.2)

$$
v_{\xi}=-F^{-1}\left(\xi_{t}\right) \zeta l_{t}^{-\eta}
$$

Differentiating the asset evolution equation (A.6)

$$
\frac{d a_{t+1}}{d \xi_{t}}=R c_{t}
$$

Combining these with (A.16) and the first-order condition (A.11) gives

$$
F^{-1}\left(\xi_{t}\right) \zeta l_{t}^{-\eta}=\frac{R}{1+R\left(1-\xi_{t}\right)}
$$

or

$$
\xi_{t}=F\left(\frac{R}{\zeta l_{t}^{-\eta}\left(1+R\left(1-\xi_{t}\right)\right)}\right)
$$

which defines implicitly the choice of $\xi_{t}$.

\section{A.7 The strategy for the wage}

Recall that the wage can only be chosen in periods $t=0, N, 2 N \ldots$ If we are in one of these periods the following analysis applies. Otherwise the wage is given. 
Using the utility function (A.2)

$$
v_{w}=\theta \zeta \frac{n_{t} l_{t}^{-\eta}}{w_{t}}
$$

Differentiating continuation utility (A.8) gives

$$
V_{w}=\sum_{i=1}^{N-1} \delta^{i-1}\left(\theta \frac{n_{t+i}}{w_{t}} \zeta l_{t+i}^{-\eta}\right)
$$

Assets in $t+1$ depend on the wage chosen in this period via the initial sale of labour income in (A.4) so

$$
\begin{aligned}
\frac{d a_{t+1}}{d w_{t}} & =(1+r)^{t} \frac{d a_{0}}{d w_{t}} \\
& =(1-\theta)(1-\tau) \frac{\varphi}{N} \sum_{i=0}^{N-1} \frac{n_{t+i}}{(1+\pi)^{i}}
\end{aligned}
$$

Substituting this, (A.34) and (A.16) into the first-order condition for the wage (A.12) gives

$$
\begin{aligned}
& \frac{\theta \zeta}{w_{t}}\left(n_{t} l_{t}^{-\eta}+\gamma \delta \sum_{i=1}^{N-1} \delta^{i-1} n_{t+i} l_{t+i}^{-\eta}\right)= \\
& -(1-\theta)(1-\tau) \frac{1}{c_{t}\left[1+R\left(1-\xi_{t}\right)\right]} \frac{\varphi}{N} \sum_{i=0}^{N-1} \frac{n_{t+i}}{(1+\pi)^{i}}
\end{aligned}
$$

or

$$
w_{t}=\frac{\theta \zeta}{\varphi(\theta-1)(1-\tau)} \frac{n_{t} l_{t}^{-\eta}+\gamma \delta \sum_{i=1}^{N-1} \delta^{i-1} n_{t+i} l_{t+i}^{-\eta}}{\frac{1}{c_{t}\left[1+R\left(1-\xi_{t}\right)\right]} \frac{1}{N} \sum_{i=0}^{N-1} \frac{n_{t+i}}{(1+\pi)^{i}}}
$$

Using the general discount factor $\left(\beta_{t: t}=1 \beta_{t: t+i}=\gamma \delta^{i}\right.$ for $\left.i>0\right)$ the optimal choice of the wage can be written

$$
w_{t}=\omega \frac{\sum_{i=0}^{N-1} \beta_{t: t+i} n_{t+i} l_{t+i}^{-\eta}}{\frac{1}{N c_{t}\left[1+R\left(1-\xi_{t}\right)\right]} \sum_{i=0}^{N-1} \frac{n_{t+i}}{(1+\pi)^{i}}}
$$


where

$$
\omega=\frac{\theta \zeta}{\varphi(\theta-1)(1-\tau)}
$$

\section{A.8 An infinite horizon game}

As $m \rightarrow \infty$ (recall $T=m N)$ the expression for $\lambda($ A.28) becomes

$$
\lambda_{t}=\frac{\frac{1-\delta}{\gamma \delta}}{1+\frac{1-\delta}{\gamma \delta}} \frac{1+r}{1+R\left(1-\xi_{t}\right)}
$$

In the infinite horizon game, if assets are neither to collapse or explode, and ruling out oscillatory solutions, from (A.18)

$$
\mu=1
$$

which implies from (A.19)

$$
1=(1+r)-\left[1+R\left(1-\xi_{t}\right)\right] \lambda_{t}
$$

or

$$
\lambda_{t}=\frac{r}{1+R\left(1-\xi_{t}\right)}
$$

and equating this with (A.41) gives a relation between the three time preference parameters

$$
\frac{1-\delta}{\gamma \delta}=r
$$

\section{A.9 Uniqueness}

If $\xi_{t}$ and $w_{t}$ were exogenous, (A.44) would give a unique value for $\lambda_{t}$ then (A.39) a unique value for $w_{t}$. However in general (A.32) shows that $\xi_{t}$ depends on itself both directly and via leisure. Geometrically, the left hand side of (A.32) is the $45^{\circ}$ line and since $F$ is a CDF so defined at every value on the interval $[0,1]$ there will always be at least one solution. However since there is no closed form expression for consumption or output nothing general can be said about whether there might be more than one solution. Given this, the only option is to check uniqueness 
numerically for each steady state (each value of inflation for each calibration) considered in the paper. This process is straightforward:

1. Take $\xi$ exogenous over a fine grid and at each point of the grid evaluate the right-hand side of (A.32)

2. Check it is weakly monotonic. If so, there will be a unique solution for $\xi_{t}$ and hence a unique equilibrium strategy in the chosen steady state

In practice, the right-hand side is found to be monotonically decreasing in $\xi_{t}$, implying a unique solution, for a far wider range of calibrations than that considered in the paper. 


\section{B Supplementary material}

\section{B.1 The initial wealth distribution}

In the absence of redistributive tax, different cohorts have (very slightly, under the range of inflation rates we consider in the paper) different present values of lifetime wealth. This is because, if there are two cohorts, one starts their life in the first period of the contract when income is high, and the second starts in the second period of the contract when income is low, so the present value of labour income of the first is higher than that of the second. The differences in wealth are small, but they make aggregation difficult since they imply the optimal wage would differ between cohorts. So we consider a government that sets a pattern of initial endowments to make the wealth of households equal.

In the steady state, each contract period is identical, so writing the real wage as $w^{i}$ and labour supply in period $i$ of a contract as $n_{i}$ the total flow of income in period $t$ is

$$
y_{t}=\sum_{i=0}^{N-1}\left[(1-\tau) w_{i} n_{i}+\chi_{i}\right]
$$

so the total lifetime wealth of society is the annuity value of this:

$$
A_{0}=\frac{1}{r} \sum_{i=0}^{N-1}\left[(1-\tau) w_{i} n_{i}+\chi_{i}\right]
$$

Divide this equally between cohorts so

$$
a_{0}=\frac{1}{N} A_{0}=\frac{1}{N r} \sum_{i=0}^{N-1}\left[(1-\tau) w_{i} n_{i}+\chi_{i}\right]
$$

The government redistributes wealth before the opening of the initial period to equalize each cohort's wealth at this value.

Away from the steady state, and in finite games of length $m N, m \in \mathbb{Z}^{+}$, the government announces that it will set each cohort's wealth equal to

$$
a_{0}=\sum_{j=0}^{m-1} \frac{1}{(1+r)^{m N}} z_{j}
$$


where $z_{j}$ is the discounted value of average income over the contract period starting in $t=j N$

$$
z_{j}=\frac{\varphi}{N} \sum_{t=j N}^{(j+1) N-1}\left[(1-\tau) w_{t} n_{t}+\chi_{t}\right]
$$

and $\varphi=\frac{1-(1+r)^{-N}}{1-(1+r)^{-1}}$. This reduces to (B.3) for the steady state of an infinite game. To make the steady state symmetric, households must take this redistribution into account when optimising.

\section{B.2 Deriving the labour supply relation}

In the steady state, the government's budget constraint is

$$
\chi=\frac{1}{N}\left(\tau \sum_{i=0}^{N-1} \frac{w}{(1+\pi)^{i}} n_{i}+m_{t}-\frac{m_{t-1}}{1+\pi}\right)
$$

where $n_{i}$ is the labour supplied by a household in period $i$ of its contract. From (A.44), consumption is

$$
c=\frac{r}{1+R\left(1-\xi_{t}\right)} a_{0}
$$

then given the initial wealth distribution (B.3)

$$
c=\frac{r}{1+R(1-\xi)} \frac{1}{N r} \sum_{t=0}^{N-1}\left[(1-\tau) w_{t}(i) n_{t}(i)+\chi_{t}\right]
$$

Substituting for transfers from the government budget constraint

$$
c=\frac{1}{1+R(1-\xi)} \frac{1}{N} \sum_{i=0}^{N-1}\left[w_{t}(i) n_{t}(i)+m_{t}-\frac{m_{t-1}}{1+\pi}\right]
$$

By inspection of the asset evolution equation, seigniorage revenue in each period is

$$
m_{t}-\frac{m_{t-1}}{1+\pi}=R(1-\xi) c
$$


Substituting this gives

$$
c=\frac{1}{N} \sum_{i=0}^{N-1} \frac{w}{(1+\pi)^{i}} n^{i}
$$

Substituting this into the expression for the optimum wage (A.39), reproduced here

$$
w_{t}=\omega \frac{\sum_{i=0}^{N-1} \beta_{t: t+i} n_{t+i} l_{t+i}^{-\eta}}{\frac{\varphi}{c_{t}\left(1+R\left(1-\xi_{t}\right)\right) N} \sum_{i=0}^{N-1} \frac{n_{t+i}}{(1+\pi)^{i}}}
$$

gives

$$
\frac{\varphi}{\omega[1+R(1-\xi)]}=\sum_{i=0}^{N-1} \beta_{i}\left(1-n^{i}\right)^{-\eta} n^{i}
$$

To calibrate $\zeta$ write this expression in a steady state with zero inflation so $n^{i}=n \forall i$ and $n$ is steady state labour

$$
\omega=\frac{\varphi}{[1+R(1-\xi)](1-n)^{-\eta} n \sum_{i=0}^{N-1} \beta_{i}}
$$

and using the definition of $\omega$

$$
\zeta=\frac{\omega(\theta-1)(1-\tau)}{\theta \varphi}
$$

\section{B.3 Checking the bond market clears}

Households exchange bonds to smooth consumption in the face of non-smooth income. In the steady state, the net supply for bonds from cohort $i$ is given by the difference between consumption and income

$$
b^{s}(i)=\frac{w^{*}}{(1+\pi)^{i}} n_{i}-c^{*}
$$

where consumption $c^{*}$ is constant across time and across cohorts.

Summing this across cohorts

$$
b^{s}=\sum_{i=0}^{N-1} \frac{w^{*}}{(1+\pi)^{i}} n_{i}-N c^{*}
$$


which is zero from the definition of smoothed consumption (B.11).

\section{B.4 Deriving the social welfare function}

We define the social welfare function as a sum over all $N$ selves in all $N$ cohorts.

\section{B.4.1 Utility from the perspective of selves at $t=0$}

In the steady state, the only variation in instantaneous utility across households is according to which period of the wage contract they are in. so let $u(0)$ be the utility of a household who set their wage in the current period, $u(1)$ be the utility of a household who set their wage in the previous period and $u(N-1)$ the utility of a household who set their wage $N-1$ periods ago. Then the lifetime utility of a household who reset their wage in the current period is

$$
U_{t=0}(0)=u(0)+\gamma\left[\sum_{i=1}^{N-1} \delta^{i} u(i)+\delta^{N} \sum_{i=0}^{N-1} \delta^{i} u(i)+\delta^{2 N} \sum_{i=0}^{N-1} \delta^{i} u(i)+\ldots\right]
$$

That of a household who reset their wage in the previous period is

$$
U_{t=0}(1)=u(1)+\gamma\left[\sum_{i=2}^{N-1} \delta^{i} u(i)+\delta^{N-1} \sum_{i=0}^{N-1} \delta^{i} u(i)+\delta^{2 N-1} \sum_{i=0}^{N-1} \delta^{i} u(i)+\ldots .\right.
$$

and that of a household who reset their wage $N$ periods ago

$$
U_{t=0}(N-1)=u(N-1)+\gamma\left[\delta \sum_{i=0}^{N-1} \delta^{i} u(i)+\delta^{N+1} \sum_{i=0}^{N-1} \delta^{i} u(i)+\ldots .\right]
$$

The utility of society as a whole (from the perspective of selves at time $t$ ) is, normalizing the number of households in each cohort to 1 , then summing across 
households in each period

$$
\begin{aligned}
U_{t=0} & =\sum_{i=0}^{N-1} U_{t=0}(i) \\
& =\sum_{i=0}^{N-1} u(i)+\gamma \delta \sum_{i=0}^{N-1} u(i)+\gamma \delta^{2} \sum_{i=0}^{N-1} u(i)+\ldots \\
& =1+\gamma \frac{\delta}{1-\delta} \sum_{i=0}^{N-1} u(i)
\end{aligned}
$$

Using the expression for the steady state interest rate (A.45) this can be written

$$
U_{t=0}=(1+r) \sum_{i=0}^{N-1} u(i)
$$

\section{B.4.2 Utility from the perspective of $\mathrm{t}=1$}

If households "discount" past utility flows by some constant factor $\zeta<1$, at $t=1$ the utility of the household who reset its wage in the previous period will be

$U_{t=1}(1)=\zeta u(0)+u(1)+\gamma\left[\sum_{i=2}^{N-1} \delta^{i} u(i)+\delta^{N-1} \sum_{i=0}^{N-1} \delta^{i} u(i)+\delta^{2 N-1} \sum_{i=0}^{N-1} \delta^{i} u(i)+\ldots.\right]$

that of the household that reset its wage two periods ago would be

$U_{t=1}(2)=\zeta u(1)+u(2)+\gamma\left[\sum_{i=3}^{N-1} \delta^{i} u(i)+\delta^{N-1} \sum_{i=0}^{N-1} \delta^{i} u(i)+\delta^{2 N-1} \sum_{i=0}^{N-1} \delta^{i} u(i)+\ldots\right]$

so social welfare will be

$$
\begin{aligned}
U_{t=1} & =\sum_{i=0}^{N-1} U_{t=1}(i) \\
& =(\zeta+1+r) \sum_{i=0}^{N-1} u(i)
\end{aligned}
$$


We can extend this argument to a general period

$$
\begin{aligned}
U_{t=j} & =\sum_{i=0}^{N-1} U_{t=j}(i) \\
& =\left(\zeta^{j}+\ldots+\zeta+1+r\right) \sum_{i=0}^{N-1} u(i)
\end{aligned}
$$

\section{B.4.3 The social welfare function}

Define social welfare as

$$
\begin{aligned}
U & =\sum_{j=0}^{N-1} U_{t=j} \\
& =\left[\zeta^{N-1}+2 \zeta^{N-2}+\ldots+(N-1) \zeta+N(1+r)\right] \sum_{i=0}^{N-1} u(i)
\end{aligned}
$$

So social welfare, the sum over all $N$ selves in all $N$ cohorts, reduces to a sum of the utility of a representative household from each of the $N$ cohorts. 